\title{
Heart Rate Variability in Men with Erectile dysfunction
}

\author{
Ji Yong Lee, Kwan-Joong Joo' ${ }^{1}$, Jin Tae Kim², Sung Tae Cho ${ }^{3}$, Dae Sung Cho, Yong-Yeun Won, Jong Bo Choi \\ Department of Urology, Ajou University School of Medicine, Suwon; \\ ${ }^{1}$ Department of Urology, Kangbuk Samsung Hospital, Sungkyunkwan University School of Medicine, Seoul; \\ ${ }^{2}$ Kyonggi University Graduate School of Sports Science, Suwon; \\ ${ }^{3}$ Department of Urology, Hallym University School of Medicine, Seoul, Korea
}

Purpose: The objective of this study is to investigate alteration of autonomic nervous system (ANS) activity in patients suffering from erectile dysfunction (ED) by comparing parameters of heart rate variability (HRV) between men with ED and healthy subjects.

Methods: A retrospective review was performed on $40 \mathrm{ED}$ patients (mean age, $46.0 \pm 8.49$ years) without any disease and 180 healthy control people (mean age, $44.4 \pm 7.83$ years) without ED in our institution from June 2008 to July 2010. And electrocardiographic signals were obtained to measure HRV parameters for both patients and controls in a resting state.

Results: For the time domain analysis, square root of the mean differences between successive RR intervals (RMSSD) representing parasympathetic activity was lower in patients than controls although $\mathrm{P}$-value was not statistically significant $(\mathrm{P}=0.060)$. For the frequency domain analysis, high frequency (HF) representing parasympathetic activity was lower in patients than controls $(\mathrm{P}=0.232)$ and low frequency $(\mathrm{LF})$ representing mainly sympathetic activity was higher in patients than controls $(\mathrm{P}=0.416)$. Lastly, LF/HF ratio reflecting sympathetic/parasympathetic activity ratio was statistically higher in patients than controls $(\mathrm{P}=$ 0.027).

Conclusions: Patients with ED exhibited different HRV parameters compared with normal controls. This suggests that the patients with ED may have some kind of imbalance in the ANS and it may be possible that general imbalance of the ANS is one of the causes of ED. Thus, HRV analysis may give valuable diagnostic information and serve as a rapid screening tool to evaluate altered ANS activity in patients with ED.

Keywords: Autonomic nervous system; Erectile dysfunction; Heart rate variability

\section{INTRODUCTION}

Erectile dysfunction (ED; or impotence) is defined as persistent inability to attain and maintain an erection sufficient for satisfactory sexual performance [1]. Epidemiologic studies of ED suggest that approximately 5 to $20 \%$ of men have moderate to severe ED. According to research, 189 million men in 2004 and 198 million men in 2006 were affected by ED globally [2,3]. From the Massachusetts Male Aging Study with 1709 noninstitutionalized men between the ages of 40 and 70 years, the probability of moderate and complete ED was 52\% [4]. In the Korean study consisted of 1,570 men aged 40 to 79 years, the preva- lence of ED were $13.4 \%$ through self-report and $32.4 \%$ through International Index of Erectile Function (IIEF)-5 score $\leq 17$ [5].

$\mathrm{ED}$ is caused by many factors such as psychogenic and organic (arteriogenic, cavernosal, neurogenic, anatomic and, endocrinologic) impairments. It has been estimated that more than $80 \%$ of ED is caused by organic impairments and 10 to $19 \%$ of $\mathrm{ED}$ is neurogenic impairments [6,7]. It is known that the penis is innervated by both autonomic (sympathetic and parasympathetic) and somatic (sensory and motor) nerve, which control the neurovascular events during erection. The autonomic pathway is consisted of sympathetic nerves from the 11th thoracic to the 2nd lumbar spinal cord segments and parasympathetic
Corresponding author: Jong Bo Choi

Department of Urology, Ajou University School of Medicine, San-5

Woncheon-dong, Yeongtong-gu, Suwon 443-749, Korea

Tel: +82-31-219-5270 / Fax: +82-31-219-5276 / E-mail: urochoi@ajou.ac.kr

Submitted: June 8, 2011 / Accepted after revision: June 21, 2011
This is an Open Access article distributed under the terms of the Creative Commons Attribution Non-Commercial License (http://creativecommons.org/licenses/by-nc/3.0/) which permits unrestricted non-commercial use, distribution, and reproduction in any medium, provided the original work is properly cited. 
nerves from the 2nd to 4th sacral spinal cord segments [6]. Physiologically, there are three types of erections: nocturnal, psychogenic, and reflexogenic erection. They are controlled by central nervous system, spinal erection centers (T11-L2 and S2S4) or both. Thus, changes in autonomic nervous system (ANS) activity may contribute to the cause of ED.

Heart rate variability (HRV) is widely used as a noninvasive tool that shows the balance of the cardiovascular system controlled by the sympathetic and parasympathetic divisions of the ANS [8]. It also can be used as a method for quantitative assessment of the ANS analysis because primary neural control of the heart is maintained by the ANS [9]. Based on that theory, several studies have been reported to screen neurogenic erectile dysfunction by using of HRV.

Thus, in this study, we measured and compared parameters of HRV between ED patients without any disease and healthy subjects to investigate whether the patients suffering from ED have altered ANS activity through HRV measurement.

\section{MATERIALS AND METHODS}

\section{Subjects and Study Design}

This study was conducted by the Institutional Review Board of Ajou University Hospital. From June 2008 to July 2010, patients visiting to the urology outpatient clinic with erectile problems and healthy subjects visiting to the family medicine outpatient clinic for general health examination were evaluated with detailed medical history and physical examination in both clinics. The diagnosis of recruited patients with ED was made by a single urologist. People with less than 26 scores in the erectile function domain of IIEF (International Index of Erectile Function) questionnaire were diagnosed as ED patient and they actually have been suffered from penile erection for at least 6 months [10]. The following subjects were excluded from the study: those who 1) had history of neurologic disease, malignancy, endocrinopathy, coronary heart disease, arrhythmia, diabetes mellitus and heart failure, which may influence ANS, 2) were on medication with drugs affecting ANS or erectile function such as $\beta$-receptor agonists or antagonists, angiotensin-converting enzyme inhibitors, anticholinergics, calcium channel blockers or 5-alpha-reductase inhibitor within 1 month, 3) had history of surgery, irradiation or trauma to the pelvic bone, penis, urethra or prostate and 4) showed signs of dehydration. Then, we selected 40 men with ED as patients and 180 men without ED as controls retrospectively. All patients of the control group had an
IIEF-EF score above 26.

\section{HRV Measurements}

Autonomic functions were assessed by HRV. Subjects were kept in a quiet test room at the beginning of the test after 30 minutes resting time. Before the test, they were restricted from drinking coffee or tea, smoking and taking drugs which can influence ANS. While subjects were breathing normally in a sitting position, electrocardiography was recorded for 5 minutes and then analyzed by SA-3000P (Medicore Inc., Seoul, Korea) [11-13]. The digitized electrocardiography signals were analyzed by online database and stored on a hard disk for offline verification simultaneously. Two main analyses are performed for HRV: time domain and frequency domain analysis [14]. To compare the time domain indexes, we used mean heart rate (HR) in bpm, the standard deviation of all normal RR intervals (SDNN), and the square root of the mean differences between successive RR intervals (RMSSD). The unit of the time domain measurement was set as milliseconds. SDNN reflects both sympathetic and parasympathetic activities and RMSSD reflects parasympathetic activity only [10]. To compare the frequency of domain indexes, we used very low frequency (VLF), low frequency (LF), high frequency (HF) and the low-frequency/high-frequency ratio (LF/HF ratio). The unit of the frequency domain measurements was set as millisecond square. LF (0.04 to $0.15 \mathrm{~Hz}$ ) band reflects both sympathetic and parasympathetic activity and is associated with baroreflex activity. HF ( 0.15 to $0.4 \mathrm{~Hz})$ band reflects cardiac vagal tonus and is associated with respiration-related heart rate changes (respiratory sinus arrhythmia). LF/HF ratio reflects sympathetic/parasympathetic activity ratio [14]. The parameters of HRV were measured retrospectively.

\section{Statistical Analysis}

Statistics were performed by using SPSS ver. 12.0 (SPSS Inc., Chicago, IL, USA). The data were presented as mean \pm standard deviation (SD). Comparisons between the two groups were performed with the unpaired t-test. P-value less than 0.05 was considered as significant result statistically.

\section{RESULTS}

The t-test revealed that there was no significant difference between the two groups according to age. Mean \pm SD of the 40 men with $\mathrm{ED}$ was $46.0 \pm 8.5$ years old and 180 men without $\mathrm{ED}$ was $44.4 \pm 7.8$ years old $(P=0.259)$. There was no significant differ- 
ence in body mass index (BMI), either. BMI of the men with ED was $25.7 \pm 1.3 \mathrm{~kg} / \mathrm{m}^{2}$ and men without ED was $24.3 \pm 1.5$ $\mathrm{kg} / \mathrm{m}^{2}(\mathrm{P}=0.427)$. Complete blood count, routine blood chemistry and urinalysis results were normal in both groups. For the time domain, HR or SDNN was not statistically significant, but RMSSD (index to represent parasympathetic activity) was lower in patients than controls (patients, 22.1 \pm 12.6 ; controls, 26.5 \pm 13.3) even though $\mathrm{P}$-value was not statistically significant $(\mathrm{P}=$ 0.060 ). For the frequency domain, VLF, LF, and HF value showed no statistically significant difference. HF representing parasympathetic activity was lower in patients than controls $(\mathrm{P}=0.232)$ and LF representing mainly sympathetic activity was higher in patients than controls $(\mathrm{P}=0.416)$. However, LF/HF ratio (index to reflect sympathetic/parasympathetic activity ratio) was statistically higher in patients than controls (patients, $3.4 \pm 3.2$; controls, $2.3 \pm 2.7 ; \mathrm{P}=0.027$ ) (Table 1).

\section{DISCUSSION}

Physiologically, normal erections are consisted of three types: psychogenic, reflexogenic, and nocturnal. Psychogenic erection is a result of audiovisual stimuli or fantasy. Impulses from the brain modulate the spinal erection centers (T11-L2 and S2-S4) to activate the erectile process. Reflexogenic erection is produced by tactile stimulation of the genital organs. A stimulation percept from sensory receptors reaches to the spinal erection center, followed by the ascending tract. Then, messages are sent

Table 1. The results of parameters of heart rate variability and basic characteristics between the patients and controls

\begin{tabular}{lccc}
\hline Variable & Patients $(\mathrm{n}=40)$ & Controls $(\mathrm{n}=180)$ & P-value \\
\hline Age $(\mathrm{yr})$ & $46.0 \pm 8.5$ & $44.4 \pm 7.8$ & 0.259 \\
BMI $\left(\mathrm{kg} / \mathrm{m}^{2}\right)$ & $25.7 \pm 1.3$ & $24.3 \pm 1.5$ & 0.427 \\
HR $(\mathrm{bpm})$ & $74.4 \pm 12.7$ & $71.4 \pm 13.9$ & 0.208 \\
SDNN $(\mathrm{ms})$ & $33.1 \pm 15.0$ & $36.5 \pm 14.4$ & 0.172 \\
RMSSD $(\mathrm{ms})$ & $22.1 \pm 12.6$ & $26.5 \pm 13.3$ & 0.060 \\
VLF $\left(\mathrm{ms}^{2}\right)$ & $491.5 \pm 587.0$ & $402.6 \pm 260.7$ & 0.158 \\
LF $\left(\mathrm{ms}^{2}\right)$ & $299.1 \pm 342.3$ & $263.9 \pm 218.5$ & 0.416 \\
HF $\left(\mathrm{ms}^{2}\right)$ & $160.2 \pm 192.2$ & $199.7 \pm 187.4$ & 0.232 \\
LF/HF ratio & $3.4 \pm 3.2$ & $2.3 \pm 2.7$ & 0.027 \\
\hline
\end{tabular}

Values are presented as mean $\pm \mathrm{SD}$.

BMI, body mass index; HR, heart rate; SDNN, standard deviation of all normal RR intervals; RMSSD, square root of the mean differences between successive RR intervals; VLF, very low frequency; LF, low frequency; HF, high frequency. through the cavernous nerves. Nocturnal erection occurs mostly during rapid-eye-movement (REM) sleep. During REM sleep, the cholinergic neurons in the lateral pontine tegmentum are activated, and the adrenergic neurons in the locus ceruleus and the serotonergic neurons in the midbrain raphe are silent. This differential activation may be responsible for nocturnal erection [6]. From these normal erection processes, it is known that erections are influenced by ANS. Several studies have been conducted to investigate the relation between ED and ANS and found the alteration of ANS activity in patients with ED through HRV. Because computed components of HRV are noninvasive and reliable, $\mathrm{HRV}$ it is one the most popular indicators for assessing the activities of the ANS [10].

HRV depends on the influence of sympathetic and vagal activity on the sinus node, and variability reflects spontaneous changes in autonomic activity [13]. The clinical significance of HRV was first recognized in 1965 by Hon and Lee who noted that fetal distress is preceded by changes in the R-to- $\mathrm{R}$ intervals, which was the first indication that HRV indicates body changes or pathology [15]. And then, the Joint Task Force of the European Society of Cardiology and the North American Society of Pacing and Electrophysiology established the measurement tool of HRV, pathological analysis and standard of clinical use in 1996 [9].

Lavie et al. [16] reported that there is a relative decrease in the activity of the parasympathetic division combined with a dramatic increase in the activity of the sympathetic division in patients with organic erectile dysfunction during sleeping. Giuliano and Rampin [17] suggested that sympathetic pathways play an anti-erectile role while parasympathetic pathways play a pro-erectile role. Fernández et al. [18] reported the similar results from control group $(n=17)$ and patients with erectile dysfunction $(n=15)$ defined by IIEF-EF less than 26 . When sympatho-vagal balance expressed as LF/HF ratio was compared between the two groups under three different body positions (supine, seated, and standing position), LF/HF ratio of the disease subject was increased dramatically. Dogru et al. [14] reported that ED group had significantly higher value of sympathetic activity indicator (LF/HF ratio) than the control group, but there was no difference between the two groups in terms of parasympathetic activity indicator (HF). These results support the idea that ED patients have excessive sympathetic activity and out study had similar results. Dogru and Basar [10] also reported that hyperlipidemic patients with ED had diminished nocturnal parasympathetic activities and increased nocturnal 
sympathetic activity through HRV parameters. Chen et al. [19] reported similar results to the above findings. The patients with non-organic ED revealed a significantly lower HF and a significantly higher LF/HF, compared with the healthy group. All the HRV parameters of the patients with a satisfactory response after treatment of a two-month oral trazodone (50 to $200 \mathrm{mg}$, each night) have significantly improved. These results including our findings suggest that patients with ED have significant cardiac sympathetic hyperactivity and cardiac vagal impairment and sympathovagal dysfunction in them may not be only confined to the sexual organs, but is likely to be systemic.

In this study, we detected that among the HRV parameters, LF/HF ratio was statistically higher in patients with ED than controls. RMSSD and HF representing parasympathetic activity were lower in patients than controls and LF representing mainly sympathetic activity was higher in patients than controls although P-values were not statistically significant. These results suggest that men with ED may have some kind of imbalance in the ANS and it may be possible that general imbalance of the ANS is one of the causes of ED.

This study has several limitations. First, this study was conducted in the single center. Second, the sample size of both groups was small. Third, despite exclusion criteria for drugs that affect autonomic activity, we could not control individual emotion, mental state and environmental factors during measurement of HRV. Fourth, electrocardiography recording was measured only for 5 minutes in a sitting position not for 24 hours to simplify the measurement and reduce discomfort of subjects. Last, we only compared subjects with and without $\mathrm{ED}$ not to distinguish between organic and non-organic ED. However, this study is the first report in Korea showing that autonomic variability occurs with ED. Further studies with larger sample size and animal experiments are needed to confirm our results.

\section{CONFLICT OF INTEREST}

No potential conflict of interest relevant to this article was reported.

\section{REFERENCES}

1. Lue TF, Giuliano F, Montorsi F, Rosen RC, Andersson KE, Althof S, et al. Summary of the recommendations on sexual dysfunctions in men. J Sex Med 2004;1:6-23.
2. Hatzimouratidis K, Amar E, Eardley I, Giuliano F, Hatzichristou D, Montorsi F, et al. Guidelines on male sexual dysfunction: erectile dysfunction and premature ejaculation. Eur Urol 2010;57:804-14.

3. Selvin E, Burnett AL, Platz EA. Prevalence and risk factors for erectile dysfunction in the US. Am J Med 2007;120:151-7.

4. Feldman HA, Goldstein I, Hatzichristou DG, Krane RJ, McKinlay JB. Impotence and its medical and psychosocial correlates: results of the Massachusetts Male Aging Study. J Urol 1994;151:54-61.

5. Ahn TY, Park JK, Lee SW, Hong JH, Park NC, Kim JJ, et al. Prevalence and risk factors for erectile dysfunction in Korean men: results of an epidemiological study. J Sex Med 2007;4:1269-76.

6. Wein AJ, Kavoussi LR, Novick AC, Partin AW, Peters CA, editors. Campbell-Walsh urology. 9th ed. Philadelphia: Saunders; 2007.

7. Quam JP, King BF, James EM, Lewis RW, Brakke DM, Ilstrup DM, et al. Duplex and color Doppler sonographic evaluation of vasculogenic impotence. AJR Am J Roentgenol 1989;153:1141-7.

8. van Ravenswaaij-Arts CM, Kollée LA, Hopman JC, Stoelinga GB, van Geijn HP. Heart rate variability. Ann Intern Med 1993;118:43647.

9. Task Force of the European Society of Cardiology and the North American Society of Pacing and Electrophysiology. Heart rate variability: standards of measurement, physiological interpretation and clinical use. Circulation 1996;93:1043-65.

10. Dogru MT, Basar MM. Comparison of the differences in circadian autonomic function in hyperlipidemic men with and without erectile dysfunction. Int Urol Nephrol 2010;42:589-96.

11. Kim IH, Kim JT, Lee SH, Kim SJ, Kim YS, Choi JB. The relation between autonomic nervous system activity and lower urinary tract symptoms: an analysis of heart rate variability in men with lower urinary tract symptoms. Korean J Urol 2009;50:475-9.

12. Im HW, Kim MD, Kim JC, Choi JB. Autonomous nervous system activity in women with detrusor overactivity. Korean J Urol 2010; 51:183-6.

13. Choi JB, Kim YB, Kim BT, Kim YS. Analysis of heart rate variability in female patients with overactive bladder. Urology 2005;65:1109-12.

14. Dogru T, Kocak OM, Erberk-Ozen N, Basar M. Assessment of the autonomic nervous system is an appropriate biological marker for the well-being in erectile dysfunction. Asian J Androl 2008;10:643-50.

15. Hon EH, Lee ST. Electronic evaluation of the fetal heart rate. VIII. Patterns preceding fetal death, further observations. Am J Obstet Gynecol 1963;87:814-26.

16. Lavie P, Shlitner A, Nave R. Cardiac autonomic function during sleep in psychogenic and organic erectile dysfunction. J Sleep Res 1999;8:135-42.

17. Giuliano F, Rampin O. Neural control of erection. Physiol Behav 
2004;83:189-201.

18. Fernández EA, Souza Neto EP, Abry P, Macchiavelli R, Balzarini M, Cuzin B, et al. Assessing erectile neurogenic dysfunction from heart rate variability through a Generalized Linear Mixed Model frame- work. Comput Methods Programs Biomed 2010;99:49-56.

19. Chen CJ, Kuo TB, Tseng YJ, Yang CC. Combined cardiac sympathetic excitation and vagal impairment in patients with non-organic erectile dysfunction. Clin Neurophysiol 2009;120:348-52. 